\title{
Interferon-Free Regimens in the Liver-Transplant Setting
}

\author{
Sabela Lens, MD ${ }^{1}$ Martina Gambato, MD ${ }^{1} \quad$ María-Carlota Londoño, MD ${ }^{1} \quad$ Xavier Forns, MD ${ }^{1}$ \\ ${ }^{1}$ Liver Unit, Hospital Clinic, IDIBAPS and CIBEREHD, Barcelona, Spain \\ Address for correspondence Xavier Forns, MD, Liver Unit, Hospital Clinic, \\ CIBEREHD, IDIBAPS, Barcelona, Spain (e-mail: xforns@clinic.ub.es).
} Semin Liver Dis 2014;34:58-71.

\begin{abstract}
During 2014 and 2015, different interferon- (IFN-) free regimens will be approved for use in chronic hepatitis C (HCV). The liver-transplantation (LT) setting is the field of hepatology where these regimens will have the highest and fastest impact. Indeed, one study using direct-acting antivirals has already proven the concept that graft HCV infection can be prevented by treating patients awaiting LT. Safety and efficacy of several IFN-free regimens are currently being assessed in patients with hepatitis C

\section{Keywords}

- direct-acting antivirals cirrhosis

- liver transplantation

- sustained virological response

- adverse events recurrence after LT, with good preliminary results. Nevertheless, there are some issues that need to be addressed in the peri-LT setting and are reviewed in this article: (1) efficacy of IFN-free regimens in patients with advanced cirrhosis and portal hypertension, (2) pharmacokinetics of new antivirals in patients with several grades of hepatic or renal impairment, (3) impact of the selection of drug-resistant HCV strains in patients with decompensated cirrhosis or with severe hepatitis C recurrence after LT, and (4) drug-drug interactions.
\end{abstract}

In recent years, the use of direct-acting antivirals (DAAs) has been a major step forward in the treatment of chronic hepatitis $C$. The combination of several of these drugs in the absence of interferon (IFN; IFN-free regimens), has shown high sustained virological response (SVR) rates and a significantly better tolerance when compared with IFN-containing regimens. ${ }^{1}$

One area with an urgent need to assess the safety and efficacy of IFN-free regimens is the peri-liver transplantation (LT) setting. HCV recurrence is universal after LT in individuals with detectable HCV RNA at the time of $\mathrm{LT}^{2}$ and the consequences of graft infection are well known. Graft and patient survival are significantly lower in HCV-infected liver transplant recipients as compared with individuals who undergo LT for other indications. In approximately one-third of HCVinfected LT recipients, graft cirrhosis develops within the first 5 years following transplantation ("rapid fibrosers"). ${ }^{3}$

Treatment of HCV infection in the peri-transplant setting is indicated in two different situations. First, in patients awaiting LT to prevent HCV infection of the graft; second, in patients with hepatitis $C$ recurrence after $\mathrm{LT}$ in whom $\mathrm{HCV}$ related graft damage has already occurred. Current IFN-based regimens are very disappointing in both situations. Thus, there is plenty of room for improvement. ${ }^{4}$ In the last few months, the first data on the safety and efficacy of an IFN-free regimen (sofosbuvir plus ribavirin [RBV]) in patients awaiting LT and in individuals with hepatitis $C$ recurrence after LT have been presented. In the near future, other regimens will be evaluated in this setting. Here we will review the current status and future therapies in this group of patients.

\section{Treatment of Patients Awaiting Liver Transplantation}

Patients with advanced cirrhosis, particularly those who are awaiting a LT, are one of the most difficult-to-treat populations. The main aim of antiviral treatment while on the waiting list is to prevent HCV infection of the graft. Most centers indicate therapy for a short period to achieve undetectable HCV RNA at the time of LT; the latter is associated with a high chance of preventing graft infection following transplantation. ${ }^{5}$ A second aim of antiviral therapy in these patients is to improve liver function (which might, in some cases, imply delisting). Although this has been clearly
Issue Theme New Hepatitis C Therapies; Guest Editor, Jean-Michel Pawlotsky, MD, PhD
Copyright (C) 2014 by Thieme Medical Publishers, Inc., 333 Seventh Avenue, New York, NY 10001, USA. Tel: +1(212) 584-4662.
Dol http://dx.doi.org/ 10.1055/s-0034-1371011. ISSN 0272-8087. 
achieved in patients with HBV-related cirrhosis treated with nucleo(s)tide analogues, ${ }^{6,7}$ information on this particular topic in HCV-infected cirrhotics is insufficient. ${ }^{8}$

\section{Current Antiviral Regimens}

Current IFN-based treatments are far from optimal in patients with advanced cirrhosis. A few studies have shown that pegylated interferon (PegIFN) plus RBV administered while on the waiting list can prevent graft infection in patients who achieve viral clearance (undetectable HCV RNA). ${ }^{5,9-11}$ As expected, response rates are higher in individuals infected with HCV genotypes 2 and 3 as compared with genotype 1, as well as in those with the IL28B CC genotype. ${ }^{12}$ In those patients who achieve viral clearance, a longer duration of treatment ( $>16$ wk of therapy) is associated with lower rates of HCV recurrence after LT. ${ }^{10}$ Nevertheless, IFN-based therapy can only be administered in cirrhotics with a good liver function (Child-Pugh $\leq 7$ or Model for End-Stage Liver Disease [MELD] score $\leq 18$ ), in whom the indication of transplantation is hepatocellular carcinoma. ${ }^{3}$ In patients with more advanced disease, serious adverse events (i.e., bacterial infections such as spontaneous bacterial peritonitis or spontaneous bacteriemia, ${ }^{9}$ grade 3 and 4 cytopenias, clinical decompensation) are frequent and can be life threatening. Thus, only a small proportion of HCV-infected patients can undergo IFN-based therapy and barely $25 \%$ of them will achieve a virological response that is maintained after LT.

The recent approval of two first-wave, first-generation protease inhibitors (PIs), boceprevir and telaprevir, has been a major step forward in the treatment of chronic hepatitis C. SVR rates have increased by nearly 30\% with triple therapy as compared with PegIFN plus RBV in naïve genotype 1 patients, and by 25 to $50 \%$ in treatment-experienced genotype 1 patients (depending on previous treatment responses). ${ }^{13-17}$ Unfortunately, response rates are lower in cirrhotic patients, particularly in those who are previous null responders (a common situation in patients awaiting LT).

Beyond efficacy results, PIs-based regimens in compensated cirrhotics may be associated with serious adverse events (SAEs), such as severe infections (4-6\%), clinical decompensation (3-4\%), and even death. ${ }^{18,19}$ It is interesting to notice that the type of infections reported in cirrhotic patients treated with triple therapy did not follow the expected pattern (spontaneous bacteriemia, spontaneous bacterial peritonitis, or urinary infection caused by gram-negative bacteria). In contrast, infections of the respiratory tract or sepsis caused by gram-positive bacteria or other germs were frequently reported, some of them resulting in fatal outcomes. ${ }^{19,20}$ These serious side effects were not reported in the registration trials because patients included in these studies were mostly very well-compensated cirrhotics without significant portal hypertension (low platelet count $-<90,000$ for telaprevir ${ }^{14,15,17}$ and $<100,000$ for bocepre$\operatorname{vir}^{13,16}$-was an exclusion criterion). The main predictive factors of severe complications in cirrhotics undergoing triple therapy (severe infections, clinical decompensation, or death) were a low platelet count $\left(<100,000 / \mathrm{mm}^{3}\right)$ and low serum albumin levels $(<35 \mathrm{~g} / \mathrm{L})$. Importantly, the risk for severe complications was $44 \%$ in patients with both factors as compared with $3.4 \%$ in patients with normal platelet count and serum albumin levels. ${ }^{19}$ Overall, the data reported in these studies indicate that the proportion of patients in the waiting list that may benefit from triple therapy is very small: $<10 \%$ of genotype 1 -infected patients, slightly higher in centers with a high proportion of patients with hepatocellular carcinoma in the waiting list (M-C Londoño, unpublished results).

To date, data on triple therapy in HCV-infected patients awaiting LT are limited. Verna et $\mathrm{al}^{21}$ showed results of triple therapy in a small cohort of HCV-infected G1 cirrhotics $(n=20)$ in the waiting list for LT. Most of them were previous nonresponders and had hepatocellular carcinoma at the time of treatment initiation. Patients underwent triple therapy (90\% with telaprevir) for a median time of 14 weeks; at week 12 , up to $77 \%$ of patients had undetectable HCV RNA. Seven out of the eight transplanted patients by the time of the analysis reached LT with undetectable HCV RNA and six patients remained RNA-negative 12 weeks after transplantation. From a safety point of view, $25 \%$ of patients discontinued therapy and two of them were hospitalized due to de novo liver decompensation. A French multicenter phase II trial is assessing the safety and efficacy of boceprevir-based triple therapy (NCT 01463956$)^{22}$ in G1 patients in the waiting list with a MELD score $\leq 18$.

In summary, IFN-based regimens should be only indicated in compensated cirrhotics who are awaiting LT due to hepatocellular carcinoma; treatment in patients with more advanced disease should be restricted to those individuals with a MELD score below 18 (or Child-Pugh $\mathrm{B}<8$ points) who have a good chance to achieve a virological response (i.e., genotype $2 / 3$; genotype 1 IL28B CC). ${ }^{3,12}$ Triple therapy should be restricted to genotype 1-infected patients with compensated cirrhosis and good liver function, preferably those who are treatment-naïve, relapsers, or partial responders to previous IFN-ribavirin therapy (-Fig. 1A).

\section{Interferon-Free Regimens in Patients Awaiting LT}

\section{Efficacy of Interferon-Free Regimens in Patients with Compensated Cirrhosis}

Although data on the safety and efficacy of IFN-free regimens are very limited in decompensated cirrhotics, it is important to review the results of such regimens in compensated patients because some of them are close to regulatory approval or in late-phase 3 development.

In most phase 2 and registration trials, the proportion of patients with cirrhosis included is relatively small and most of them are treatment-naïve. In the waiting list, a significant proportion of patients are treatment-experienced (some with a first-generation PI in triple therapy) and most of them have clinically significant portal hypertension. Despite these differences, we found it was relevant to review the efficacy data of IFN-free regimens including cirrhotics, as depicted in - Table 1.23-37

In two recent published studies, ELECTRON ${ }^{28}$ and LONESTAR, ${ }^{31}$ HCV genotype 1 patients with compensated cirrhosis 
60 Interferon-Free Regimens in the Liver-Transplant Setting Lens et al.

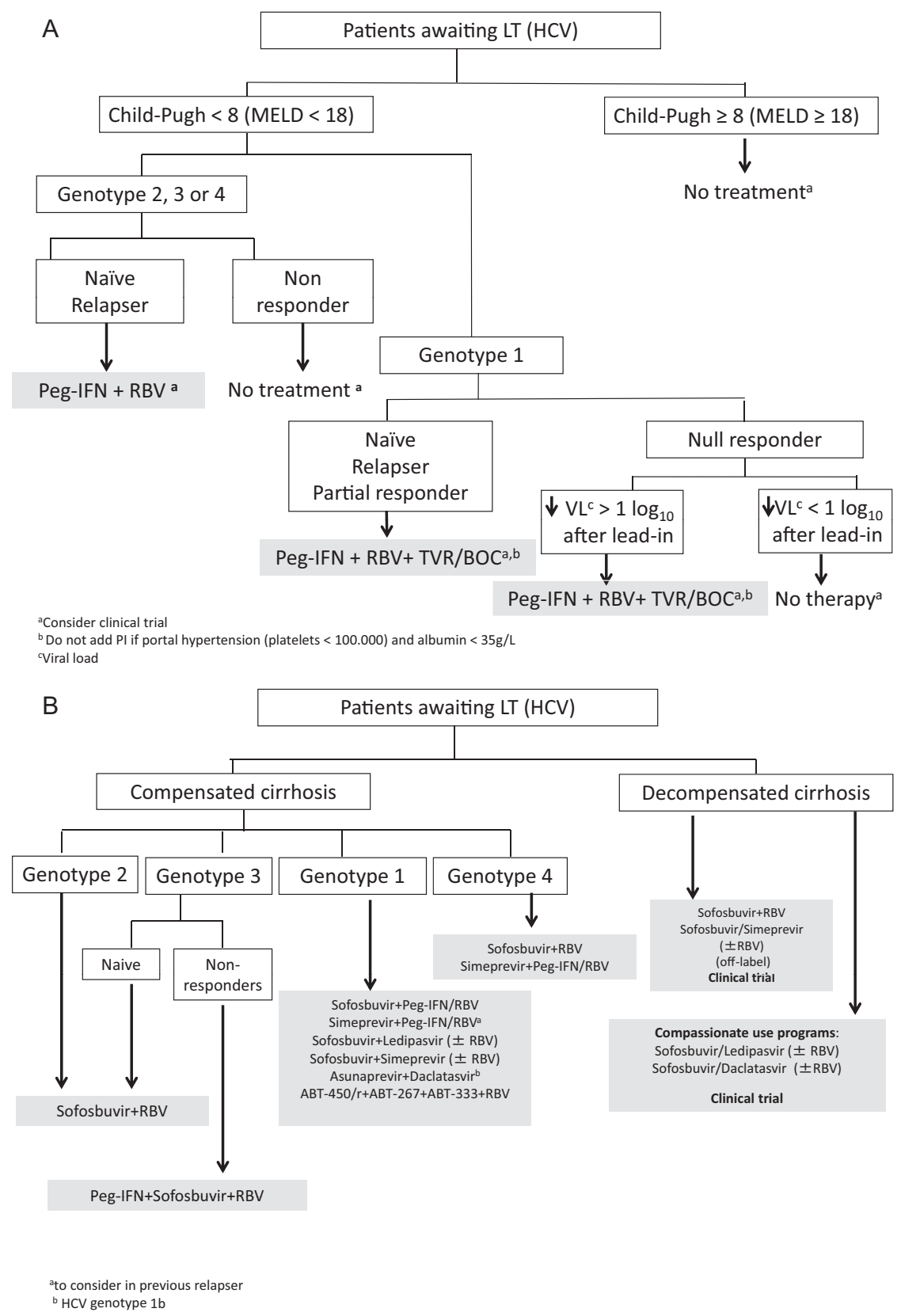

Fig. 1 Algorithm for the management of patients with hepatitis C virus (HCV) infection awaiting liver transplantation in $2013^{3}$ (A). Proposed algorithm for the management of patients with HCV infection awaiting liver transplantation in 2014-2015 (B).

who did not respond to a prior PegIFN/RBV regimen and a protease inhibitor-containing triple combination regimen, respectively, were enrolled to receive 12 weeks of sofosbuvir plus ledipasvir with or without RBV. Despite the small sample size, the results were excellent: SVR12 rates were $100 \%$ in both studies when RBV was part of the regimen, and $70 \%$ and 95\% for the ELECTRON and LONESTAR trials, respectively, when RBV was not part of the regimen. Similar results were obtained in the COSMOS study, ${ }^{30}$ in which treatment-naïve and experienced patients underwent 12 to 24 weeks of therapy with sofosbuvir and simeprevir ( $\pm \mathrm{RBV}$ ). Despite the small number of cirrhotics, SVR4 rates in the group of patients who underwent the 12-week regimens ranged between $93 \%$ and $100 \%$.
The results of a large randomized clinical trial performed in cirrhotic patients with an all-oral DAA combination (TURQUOISE II) have been recently shown (press release). ${ }^{37}$ This trial has been designed to evaluate the safety and efficacy of ABT-450 boosted with ritonavir, ABT-267, and ABT-333 coadministered with RBV for 12 or 24 weeks in HCV genotype 1infected patients with compensated cirrhosis (both treatment-naïve and experienced). SVR rates in the 12 week group were $92 \%$ and $96 \%$ in the 24 week group.

\section{Specific Features of Interferon-Free Regimens in Patients Awaiting LT}

There are some distinct features that should be taken into consideration in individuals awaiting LT. First, the goal in 


\begin{tabular}{|c|c|c|c|c|c|c|c|c|c|}
\hline 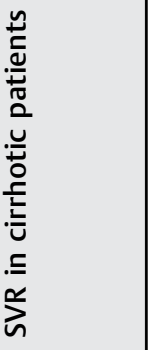 & 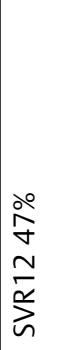 & 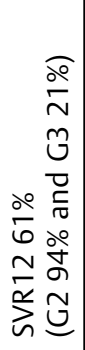 & 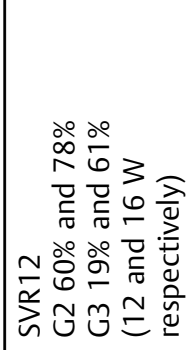 & 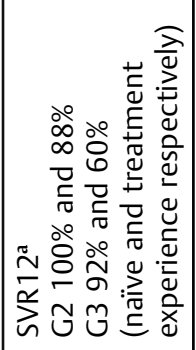 & 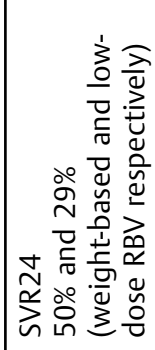 & 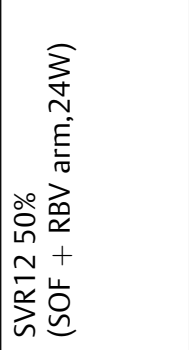 & 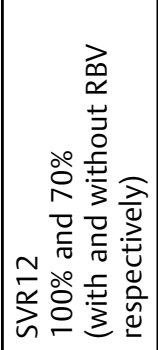 & in & 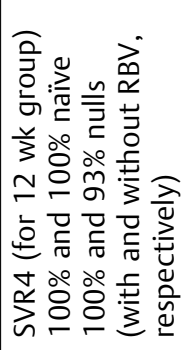 \\
\hline 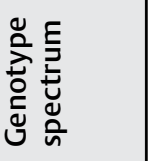 & $\stackrel{m}{\sim}$ & $\stackrel{m}{\sim}$ & $\stackrel{m}{\sim}$ & 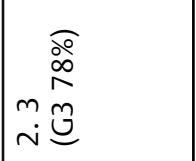 & $\begin{array}{r}\widehat{o} \\
\stackrel{0}{0} \\
-\underline{0}\end{array}$ & $\stackrel{+}{\stackrel{+}{+}}$ & - & 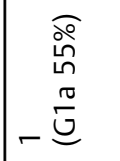 & 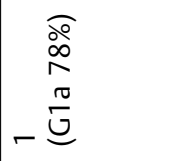 \\
\hline 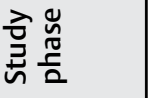 & $m$ & $m$ & $m$ & $m$ & $N$ & $\sim$ & $\sim$ & $N$ & $\sim$ \\
\hline 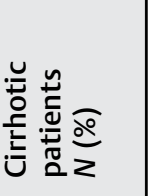 & 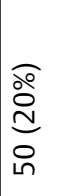 & 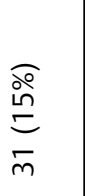 & 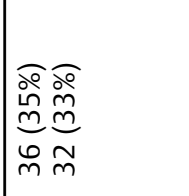 & 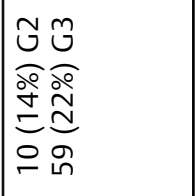 & 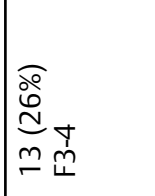 & $\begin{array}{l}\bar{o} \\
\stackrel{0}{0} \\
\bar{\sim}\end{array}$ & 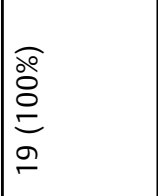 & 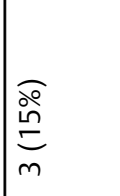 & 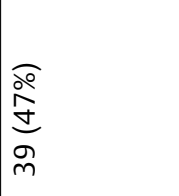 \\
\hline 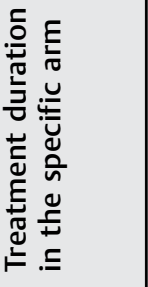 & $\begin{array}{l}3 \\
\simeq\end{array}$ & $\begin{array}{l}3 \\
\sim \\
2\end{array}$ & $\begin{array}{ll}3 & 3 \\
1 & 6 \\
1 & \end{array}$ & 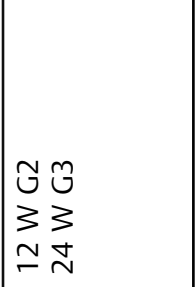 & 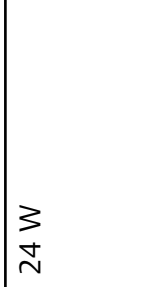 & $\begin{array}{l}33 \\
\simeq \underset{ \pm}{ }\end{array}$ & $\begin{array}{l}3 \\
\mathbb{2}\end{array}$ & $\begin{array}{l}3 \\
1 \\
I\end{array}$ & $\begin{array}{l}33 \\
\simeq \stackrel{ \pm}{N}\end{array}$ \\
\hline 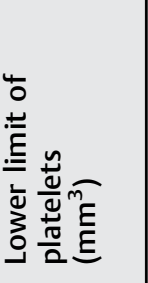 & $\begin{array}{l}8 \\
\circ \\
\stackrel{\leftrightarrow}{\wedge} \\
\wedge\end{array}$ & 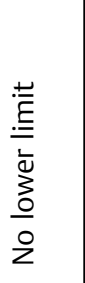 & 우․ & 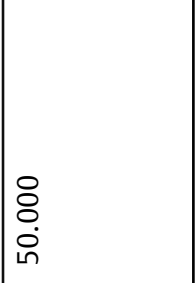 & 오․ & $\begin{array}{l}8 \\
8 \\
0 \\
\circ\end{array}$ & $\begin{array}{l}u \\
z \\
z\end{array}$ & $\begin{array}{l}8 \\
\vdots \\
\circ \\
\text { in }\end{array}$ & $\stackrel{v i}{z}$ \\
\hline 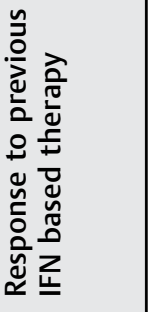 & $: \frac{⿱ 亠 䒑}{\pi}$ & 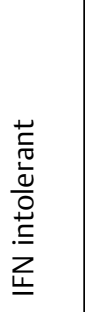 & 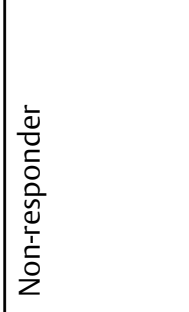 & 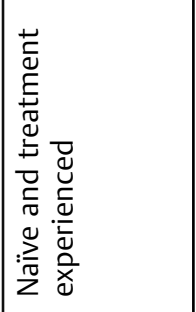 & $: \frac{0}{\pi}$ & $: \frac{\pi}{\pi}$ & 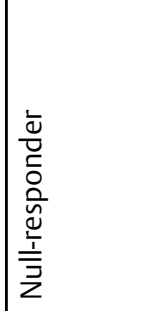 & $: \frac{\pi}{\pi}$ & 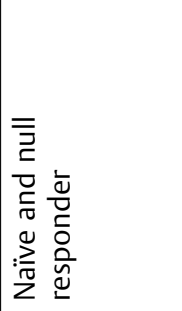 \\
\hline 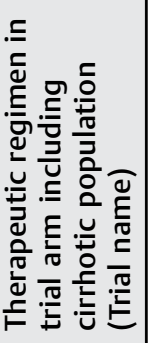 & 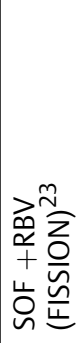 & 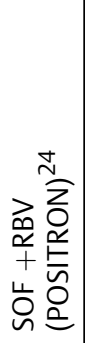 & 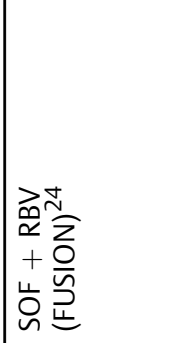 & 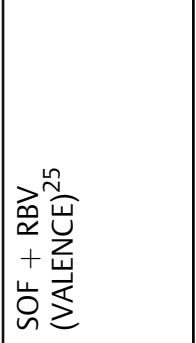 & 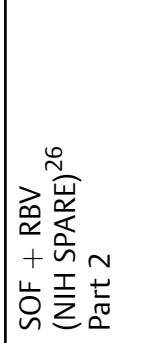 & 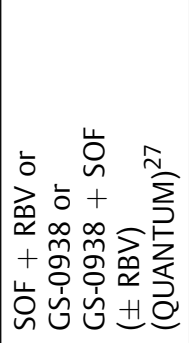 & 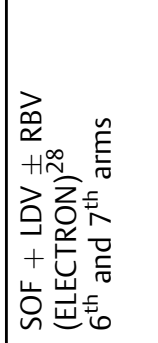 & 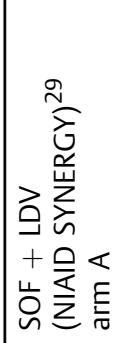 & 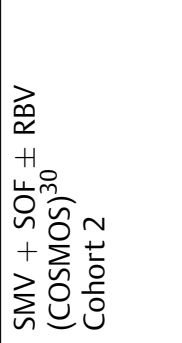 \\
\hline
\end{tabular}




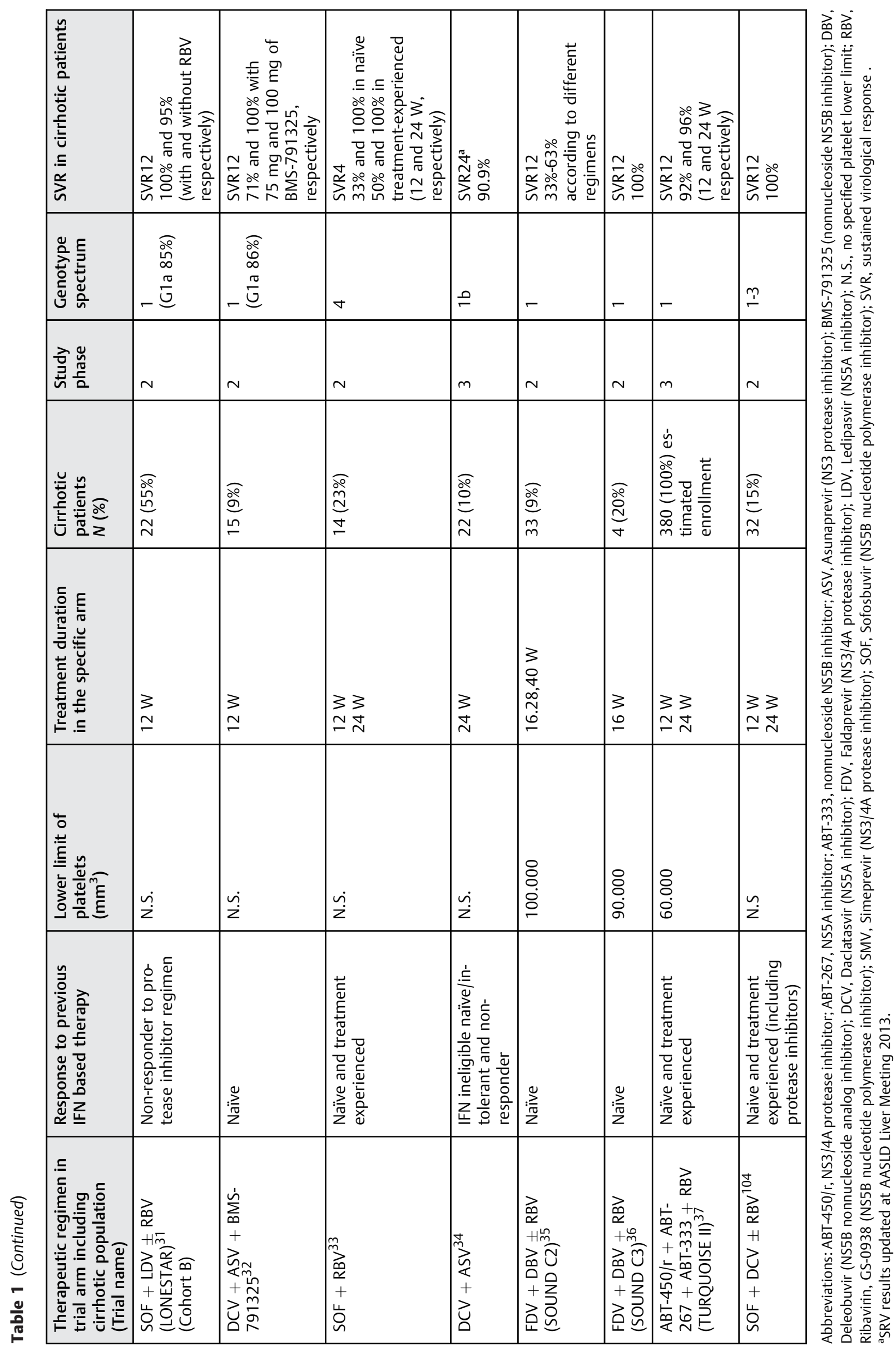


these patients is to achieve undetectable HCV RNA at the time of transplantation: Because by far the main source of viral production will be removed (liver explant), a short treatment course may be enough to prevent graft infection. In any case, a minimum length of undetectable HCV RNA before transplantation will be necessary to prevent graft infection and this will depend on viral kinetics. In the LONESTAR and ELECTRON trials, rapid virological response (RVR) rates ranged from 94 to $100 \%$ : These studies are limited for their small size, but they support the potential efficacy of a short-treatment course before LT to prevent graft infection. Nevertheless, studies in patients with significant portal hypertension are crucial because first- and second-phase HCV RNA decay may differ from patients with early cirrhosis. Indeed, the first phase viral load decline in patients awaiting LT was significantly slower than in noncirrhotic patients when treated with daily intravenous silibinin (SIL) monotherapy for 7 days (no significant differences were found between both groups for the secondphase viral decline). ${ }^{38}$ These data, however, cannot be directly translated into DAA due to the complex and multifactorial mode of action of silibinin. ${ }^{39}$ The combination of sofosbuvir plus ledipasvir and RBV is currently being assessed in patients with more advanced liver cirrhosis (Child-Pugh class B and C) in a clinical trial (NCT 01938430). ${ }^{40}$

A second distinct feature in patients with advanced liver disease is the impact of drug pharmacokinetics (PK) on liver function: Metabolic liver functions are significantly involved in the total clearance of several drugs. In fact, PK studies in patients with liver disease are an important clinical pharmacology component of drug development. In 2003, the Food and Drug Administration (FDA) released the guidance for industry on "Pharmacokinetics in Patients with Impaired Hepatic Function," which provides recommendations to sponsors on study design, data analysis, and impact on dosing and labeling. ${ }^{41}$ PK data on several new antivirals are already available ${ }^{42-56}$ and summarized in - Table 2

As an example, exposure to sofosbuvir was two-fold higher in HCV-infected patients without hepatic impairment as compared with patients with advanced liver disease. Consequently, patients with moderate and severe hepatic impairment experienced a less-profound viral decline than those with normal liver function when sofosbuvir was administered. ${ }^{54}$ These data may have clinical consequences and explain why in patients with advanced liver disease, longer treatment duration could reduce the rates of virological relapse.

A third distinct feature of patients awaiting LT is the potential risk of viral breakthrough or relapse during or after treatment, which may theoretically induce flares that could trigger liver decompensation. It is thus very relevant to choose the best treatment combination (high potency and high genetic barrier) to minimize the possibility of virological relapse or the selection of resistant-associated viral strains (RAVs). Regarding the latter point, special emphasis should be taken to avoid the selection of RAVs because they could infect the new graft and persist for prolonged time in the setting of a strong immunosuppression. The fitness of resistant strains is usually lower than that of the wild-type and sensitive virus tends to progressively replace them (except RAVs selected by NS5A inhibitors that appear to persist for a very long time). However, the presence of RAVs after transplantation may

Table 2 Pharmacokinetics of DAAs: Exposure change in hepatic and renal impairment groups versus controls

\begin{tabular}{|c|c|c|c|c|c|c|}
\hline \multirow[t]{2}{*}{ Drug } & \multicolumn{4}{|c|}{ Hepatic impairment } & \multicolumn{2}{|c|}{ Renal impairment } \\
\hline & $\begin{array}{l}\text { Mild } \\
\text { (CTP A) }\end{array}$ & $\begin{array}{l}\text { Moderate } \\
\text { (CTP B) }\end{array}$ & $\begin{array}{l}\text { Severe } \\
\text { (CTP C) }\end{array}$ & Action required & $\begin{array}{l}\text { Severe GFR } \\
\leq 30 \mathrm{~mL} / \mathrm{min}\end{array}$ & $\begin{array}{l}\text { Action } \\
\text { required }\end{array}$ \\
\hline Simeprevir $^{\mathrm{a}, 42,43}$ & $x<2$ & $\times 2.6$ & $\times 5.2$ & $\begin{array}{l}\text { Not recommended } \\
\text { in CTP-C patients }\end{array}$ & $\uparrow \times 1.62$ & No \\
\hline Faldaprevir ${ }^{\mathrm{b}, 44}$ & $x<2$ & - & - & No & $\uparrow \times<2$ & No \\
\hline Deleobuvir $^{\mathrm{b}, 45}$ & $x<2$ & - & - & No & - & - \\
\hline Asunaprevir $^{\mathrm{c}, 46,47}$ & $x<2$ & $\times 9.8$ & $\times 32.1$ & $\begin{array}{l}\text { Not recommended } \\
\text { in CTP-B or C patients }\end{array}$ & $\times 0.9$ & No \\
\hline Daclatasvir $^{\mathrm{d}, 48-50}$ & $x<2$ & $x<2$ & $x<2$ & No & - & - \\
\hline ABT-450/rd,51,52 & $x<2$ & $x<2$ & $\times 18$ & $\begin{array}{l}\text { Not recommended } \\
\text { in CTP-C patients }\end{array}$ & - & - \\
\hline ABT-267 ${ }^{d, 52}$ & $x<2$ & $x<2$ & $x<2$ & No & - & - \\
\hline ABT-333, & $x<2$ & $x<2$ & $x<2$ & No & - & - \\
\hline Sofosbuvir ${ }^{c, 53-55}$ & $x<2$ & $x<2$ & $x<2$ & No & $\uparrow \times 2$ & $\begin{array}{l}\text { Not } \\
\text { recommended }\end{array}$ \\
\hline Ledipasvir $^{56}$ & $x<2$ & $x<2^{c}$ & $x<2^{d}$ & No & - & - \\
\hline
\end{tabular}

Abbreviations: CTP, Child-Turcotte-Pugh score; GFR, glomerular filtration rate; DAAs, direct-acting antivirals.

Note: $x<2$ : twofold increase or decrease in the area under the concentration curve (AUC) is considered nonsignificant and does not need dose adjustment.

${ }^{\mathrm{a}} \mathrm{AUC} \mathrm{C}_{24 \mathrm{~h}}$ is given.

${ }^{\mathrm{b}} \mathrm{C}_{\min }$ is given.

${ }^{\mathrm{C}} \mathrm{AUC} \mathrm{C}_{\mathrm{TAU}}$ is given.

${ }^{\mathrm{d}} \mathrm{AUC} \mathrm{C}_{\text {inf }}$ is given. 
hamper antiviral therapy in case of severe hepatitis $C$ recurrence (i.e., fibrosing cholestatic hepatitis $\mathrm{C}$ ). The evolution of posttransplant HCV quasispecies in patients who failed preLT treatment with DAA should be studied carefully in the future to clarify the impact of RAVs on clinical outcomes and for the selection of the appropriate antivirals.

Finally, another aim of antiviral therapy in patients with decompensated cirrhosis should be improvement of liver function. No data are available so far, but the clinical trial assessing the safety and efficacy of sofosbuvir, ledipasvir and RBV in decompensated cirrhotics (NCT 01938430) ${ }^{40}$ will probably give us some hints in the near future. Preliminary data from the post-LT compassionate use program using sofosbuvir and ribavirin (see below) strongly suggest that viral clearance is associated with a rapid improvement in liver function.

Looking at the results of several combinations of new DAAs, it seems very likely that the use of IFN-free regimens will be able to prevent hepatitis $C$ recurrence in most patients (if not in all) awaiting LT (-Fig. 1B). The few data on IFN-free regimens in patients awaiting $\mathrm{LT}^{57-59}$ are summarized in -Table 3. Other clinical trials combining two or more DAA are ongoing in patients awaiting $\mathrm{LT}^{40,60}$

\section{Safety and Efficacy Data of Sofosbuvir and Ribavirin in Patients Awaiting LT}

The first data on the safety and efficacy of an oral IFN-free regimen in patients awaiting LT were presented at the annual American Association for the Study of Liver Diseases (AASLD) meeting in November 2013. ${ }^{57}$ In this phase-2 open-label study, 61 patients received up to 48 weeks of treatment before LT while on the waiting list (median duration 17 wk). Preliminary results can be considered excellent. Forty patients underwent LT and of these, 37 (92\%) had HCV RNA $<25 \mathrm{IU} / \mathrm{mL}$ before LT. Of them, 26 individuals reached 12 weeks of follow-up after transplantation and 18 (69\%, 90 confidence interval: 51-84\%) achieved SVR12. Seven patients $(27 \%)$ had a virological relapse and one died before reaching the endpoint. These efficacy results are encouraging and most likely, longer treatment duration and/or the addition of a second DAA (currently under evaluation with ledipasvir), will be able to prevent graft infection in most patients. Safety and tolerance of this regimen was good. The most frequently reported adverse events were mild and only one patient discontinued treatment due to anemia attributed to $\mathrm{RBV}$.

Safety and Efficacy Data of Silibinin in Patients Awaiting LT Another IFN-free regimen for patients awaiting LT was recently explored in a randomized, double-blind, placebo controlled, phase 2 trial using silibinin monotherapy. ${ }^{58}$ This natural flavonoid has been shown to exert potent antiviral properties both in vivo ${ }^{61-63}$ and in vitro. ${ }^{64}$ The study included only a very small number of patients, but demonstrated a consistent antiviral effect of intravenous silibinin and a good safety profile in these very ill patients. Despite the fact that some patients reached undetectable HCV RNA during therapy and at the time of LT, none of them had a durable response

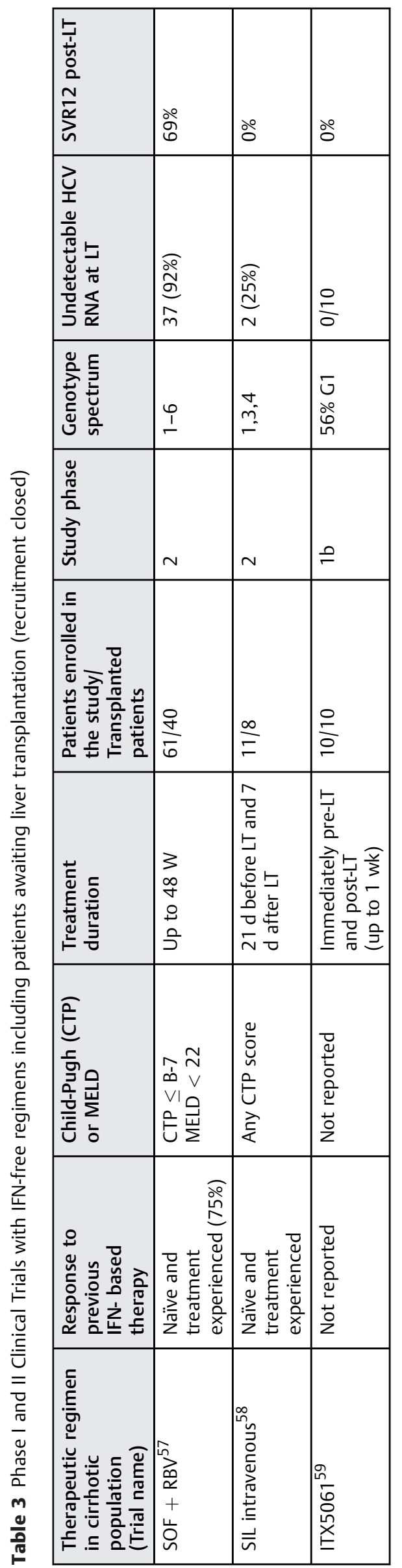


following LT. The main problem of this approach was the short treatment duration, limited by the fact that the drug needs to be administered intravenously.

\section{Treatment of HCV Recurrence after Liver Transplantation}

HCV-related cirrhosis with or without hepatocellular carcinoma is nowadays the leading indication for LT in industrialized countries. ${ }^{65}$ Virological recurrence after transplantation is constant in patients with detectable viremia at the time of $\mathrm{LT}^{2}{ }^{2}$ One of the main characteristics of hepatitis $\mathrm{C}$ recurrence after LT is the accelerated course of the disease when compared with immunocompetent patients. ${ }^{66-70}$ Approximately one third of the patients progress to graft cirrhosis within only 5 years after transplantation. ${ }^{71,72}$ This accelerated fibrosis rate impacts both the allograft and recipient survivals, which are significantly reduced when compared with nonHCV LT recipients. ${ }^{66,71,73-76}$

\section{Current Interferon-Based Regimens to Treat Hepatitis C Recurrence after LT}

The most common approach to treat hepatitis C after LT has been to start antiviral therapy once the histological damage (in particular liver fibrosis) is confirmed in the graft. The presence of significant fibrosis beyond the portal tract (METAVIR $\mathrm{F} \geq 2$ ) or portal hypertension (hepatic venous pressure gradient [HVPG] $\geq 6 \mathrm{~mm} \mathrm{Hg}$ ) one year after LT accurately identify patients at higher risk for clinical decompensation and death, ${ }^{77}$ who are at urgent need for treatment (-Fig. 2A). In patients with a severe recurrence occurring during the first months after transplantation (i.e., fibrosing cholestatic hepatitis), antiviral therapy is critical, but current treatment choices are unable to eradicate HCV in most cases and patients die or need retransplantation.

\section{Peginterferon plus Ribavirin}

The overall SVR rates with PegIFN plus RBV are low, ranging between 30 and $40 \%$ across different series. ${ }^{78-80}$ These modest virological results are mainly explained by high rates of treatment discontinuation (20-38\%), dose reductions (66$73 \%$ ), and poor tolerance or adverse events. Liver-transplant recipients are prone to hematological toxicity (particularly anemia). RBV dose reductions and the use of erythropoietin (EPO) are very frequent (75-80\%) in this setting. ${ }^{81}$ The risk of rejection is small, of the order of $\sim 5 \%$ in treated patients. ${ }^{82,83}$

Despite these results, the positive impact of SVR on survival is evident. A study performed a few years ago ${ }^{84}$

A

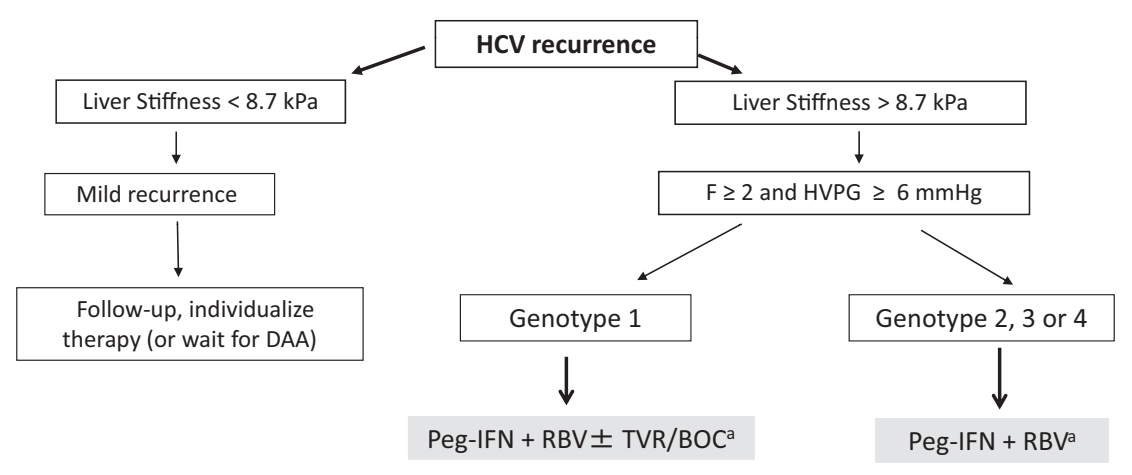

${ }^{a}$ Do not add PI if portal hypertension (platelets $<100.000$ ) and albumin $<35 \mathrm{~g} / \mathrm{L}$

B

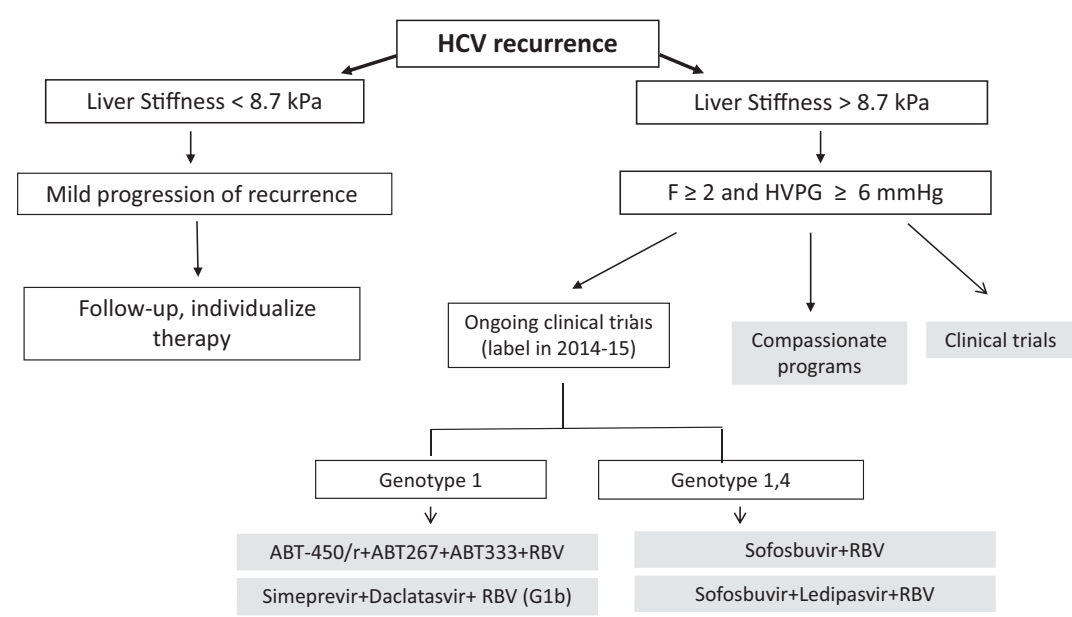

Fig. 2 Algorithm for the management of hepatitis $C$ recurrence after liver transplantation in $2013^{3}$ (A). Proposed algorithm for the management of hepatitis C recurrence after liver transplantation in 2014-2015 (B). 
assessed the impact of SVR on hepatic-venous-pressure gradient (HVPG) measured before and after antiviral treatment. Portal pressure decreased or stabilized in patients who achieved SVR compared with those who did not, in whom HVPG increased rapidly overtime. Patients achieving SVR after LT have a better survival probability compared with nonresponders. ${ }^{78}$

\section{Triple Therapy in the LT Setting}

Regarding triple therapy with PIs in the post-LT setting, results of four different series are available. ${ }^{85-90}$ These studies have evaluated the safety and efficacy of such regimens in over 300 liver-transplant recipients with hepatitis $C$ recurrence. Two-thirds of the patients received telaprevir (with or without a lead-in phase) and the rest were treated with boceprevir. Most of the patients had an advanced fibrosis stage ( $\geq$ F2) or fibrosing cholestatic hepatitis. Approximately half of the patients had received a previous course of antiviral therapy. Rapid virological response rates ranged between 53\% and $67 \%$ and, more importantly, SVR12 rates ranged between $48 \%$ and $62 \%{ }^{85-90}$ Despite these encouraging results in terms of efficacy, the major concern of triple therapy in LT recipients is the high rate of serious-adverse events leading to treatment discontinuation. Indeed, in the Canadian study, ${ }^{85} 13$ (17\%) out of the 76 patients discontinued treatment, 10 due to adverse events. Forty-three percent of the patients presented grade 3 anemia $(<8 \mathrm{~g} / \mathrm{L})$ with EPO requirement. In the European study, ${ }^{86,87} 42$ (53\%) out of the 79 the patients discontinued treatment, half of them due to adverse events. Eighty-five percent of the patients presented anemia and 95\% required EPO alone or together with ribavirin dose reduction. Six patients died during antiviral therapy. Similar safety results have also been reported by the investigators of the REFRESH ${ }^{88}$ and the CRUSH-C studies. ${ }^{89,90}$

Drug-drug interactions have become a challenge for transplant hepatologists using protease inhibitors. It is well known that CYP 3A4 isoenzymes are the most abundant in the liver and are involved in the metabolism of the majority of drugs, including cyclosporine (CsA) and tacrolimus. First- wave, first-generation PIs (telaprevir, boceprevir) are not only substrates, but are also inhibitors of this system (as well as P-glycoprotein transporter), thus strongly interacting with many drugs. Boceprevir has been shown to increase the area under the curve of CsA and tacrolimus by 2.7 and of 17 , respectively ${ }^{91}$; the figures for telaprevir are 4.6 and 70 , respectively. ${ }^{92}$ Taking into account the narrow therapeutic range of CsA and tacrolimus, dose adjustments are crucial and require very close monitoring when combined with PIs. These data, along with the experience accumulated by several groups, have been developed into general recommendations when indicating triple therapy in HCV-infected transplant patients. ${ }^{81}$

\section{New DAAs and Interferon-Free Regimens after LT}

Specific Features of IFN-Free Regimens in HCV-Infected Liver-Transplant Recipients

Treatment with IFN-free regimens in patients with hepatitis $C$ recurrence is challenging for several reasons. First, treatment may be indicated in individuals with very aggressive forms of hepatitis C (such as fibrosing cholestatic hepatitis), which occur very early after transplantation. The latter poses several difficulties because in this early period individuals are still under strong immunosuppression, at risk of opportunistic infections, not uncommonly recovering or being treated from surgical complications, and undergoing treatment with multiple drugs. Indeed, DDI is one of the most relevant issues in LT recipients, particularly due to the potential interaction of DAA with cyclosporine, tacrolimus, or other immunosuppressants. Fortunately, most anti-HCV compounds in phase 3 development have been assayed for potential interactions with CsA and tacrolimus, at least in healthy volunteers. A slight increase in sofosbuvir concentration was observed in LT-patients receiving CsA ( - Table 4). ${ }^{81,91-96}$

Renal failure is also common in liver-transplant recipients. Most patients have decreased glomerular filtration rate (GFR) due (at least in part) to the long-term use of cyclosporine or tacrolimus. Dose adjustments may be necessary in some cases

Table 4 Drug-drug interactions between DAAs and calcineurin inhibitors

\begin{tabular}{|c|c|c|c|c|c|c|}
\hline \multirow[t]{2}{*}{ DAA } & \multicolumn{3}{|c|}{ Cyclosporine } & \multicolumn{3}{|c|}{ Tacrolimus } \\
\hline & $\begin{array}{l}\text { Healthy } \\
\text { volunteers }\end{array}$ & LT recipients & $\begin{array}{l}\text { Dose } \\
\text { adjustment }\end{array}$ & $\begin{array}{l}\text { Healthy } \\
\text { volunteers }\end{array}$ & $\begin{array}{l}\text { LT } \\
\text { recipients }\end{array}$ & $\begin{array}{l}\text { Dose } \\
\text { adjustment }\end{array}$ \\
\hline Boceprevir $^{\mathrm{a}, 91,93}$ & AUC $\uparrow 2.7$-fold & $\begin{array}{l}\text { Oral clearance } \\
\downarrow 50 \%\end{array}$ & $\downarrow$ 2-fold & AUC $\uparrow 17$-fold & $\begin{array}{l}\text { Oral clearance } \\
\downarrow 80 \%\end{array}$ & $\downarrow$ 5-fold \\
\hline Telaprevir $^{\mathrm{a}, 81,92}$ & AUC $\uparrow 4.6$-fold & & $\downarrow 4$-fold & AUC $\uparrow 70$ - fold & & $\downarrow 35$-fold \\
\hline Sofosbuvir ${ }^{\mathrm{a}, 94}$ & $\begin{array}{l}\text { No significant } \\
\text { change }\end{array}$ & & Not necessary & No change & & Not necessary \\
\hline Simeprevir ${ }^{\mathrm{b}, 95}$ & AUC $\uparrow 19 \%$ & & Not necessary & AUC $\downarrow 17 \%$ & & Not necessary \\
\hline Daclatasvir $^{96}$ & No change & & Not necessary & No change & & Not necessary \\
\hline
\end{tabular}

Abbreviations: AUC, under the concentration curve; DAAs, direct-acting antivirals; LT, liver transplant.

${ }^{\mathrm{a}} \mathrm{AUC} \mathrm{C}_{\text {inf }}$ is given.

${ }^{\mathrm{b}} \mathrm{AUC} \mathrm{C}_{\text {Last }}$ is given. 
(-Table 2): Sofosbuvir, for instance, is not recommended if GFR is below $30 \mathrm{~mL} / \mathrm{min}^{55}$

A final issue that needs particular consideration in the liver transplant setting is that these patients usually have high viral loads, making it easier to select for drug-resistant strains or to develop virological relapse if the appropriate DAA combinations are not used.

\section{Sofosbuvir and Ribavirin to Treat Recurrent Hepatitis C} Sofosbuvir and RBV is the first IFN-free combination that has been assessed in hepatitis $\mathrm{C}$ recurrence in a clinical trial ${ }^{97}$ and in a compassionate-use program. ${ }^{98}$

A pilot single-arm study assessed the safety and efficacy of sofosbuvir $400 \mathrm{mg} / \mathrm{d}$ and RBV (dose escalating regimen starting at $400 \mathrm{mg} / \mathrm{d}$ ) for 24 weeks in 40 patients with HCV recurrence (any genotype) at least 6 months after LT. The study included treatment-naïve and treatment-experienced patients. Individuals with decompensated cirrhosis were excluded. The primary efficacy endpoint was SVR12.

From the 40 patients, 22 were infected with genotype 1a, 11 with genotype $1 \mathrm{~b}, 6$ with genotype 3 , and 1 with genotype 4. Most included patients had been previously treated with IFN and RBV ( 9 with PIs), mean baseline HCV RNA was 6.55 Log $10 \mathrm{IU} / \mathrm{mL}$ and $40 \%$ were cirrhotic. Despite these characteristics, by week 4 on treatment all individuals had HCV RNA $<25 \mathrm{IU} / \mathrm{mL}$. The SVR4 was $77 \%$ in the 35 individuals who had reached this time point. These results can be considered excellent, though SVR12 data are awaited, particularly due to the special RBV-dosing schedule (starting with $400 \mathrm{mg}$ ), which may facilitate virological relapse in some cases. From a safety point of view, severe adverse events (all unrelated to the study drug) occurred in $15 \%$ of individuals. Most side effects were mild; no rejection episodes occurred during therapy. ${ }^{97}$ Although there was no IFN-based control arm in the study, it is obvious that the safety and tolerance profile of this combination is significantly better than that of the current standard of care.

Preliminary results from the compassionate-use program using sofosbuvir were recently presented at an AASLD meeting. ${ }^{98}$ Sofosbuvir was provided in an institutionalreview-board-approved compassionate-use study; results from the first 45 patients who had received more than 4 weeks of treatment were presented. The antiviral regimen included sofosbuvir $400 \mathrm{mg} / \mathrm{d}$ for up to 48 weeks, with appropriate doses of RBV (PegIFN was added at the investigators' discretion). The investigators provided periodic updates on clinical status, laboratory tests, and serious adverse events. The patients included in this program differed substantially from those included in the pilot study described above because most patients had decompensated liver disease. Baseline mean bilirubin was $6 \mathrm{mg} / \mathrm{dL}$, mean albumin $21 \mathrm{~g} / \mathrm{L}$, and 19 (45\%) had histologically documented fibrosing cholestatic hepatitis. From an efficacy standpoint, the clinical condition of 32 (71\%) patients improved (significant amelioration of liver function and/or reduction/disappearance of clinical decompensation episodes). At week 4 of therapy, $\sim 75 \%$ of patients had an HCV RNA below $25 \mathrm{IU} / \mathrm{mL}$. Preliminary results based on a small group of patients who reached long-enough follow-up indicate an SVR12 of the order of $50 \%$. Seven patients (16\%) died after initiation of therapy, with all cases attributed to progression of hepatitis $C$ recurrence. Severe adverse events were frequent, but none was considered related to the study drug. Overall, the preliminary results of this program indicate that a regimen containing sofosbuvir was able to inhibit hepatitis $C$ replication in most patients and that this was associated with an improvement in the clinical condition in a significant number of them. Although longer follow-up and a higher number of patients are needed to assess the rate of SVR and its impact on disease progression, these results can be considered very encouraging. A particularly relevant result of this study was the excellent response in cases with fibrosing cholestatic hepatitis, in which deeply perturbed laboratory values (bilirubin, albumin, international normalized ratio) returned to normal a few weeks after treatment initiation and viral clearance. The latter proves the benefit of this treatment in this very severe form of HCV recurrence.

\section{Other IFN-Free Regimens in HCV-Infected LT Recipients}

There are only a few isolated reports of the use of other IFNfree regimens in the LT setting. Fontana et $\mathrm{al}^{99}$ showed for the first time the success of combined treatment with daclatasvir and sofosbuvir for 24 weeks in a LT recipient suffering from a severe HCV recurrence 8 months after LT.

Silibinin has also been used in the posttransplant setting. Barcena et al $^{100}$ have recently performed a single-center, pilot study to evaluate the safety and efficacy of intravenous silibinin monotherapy administered during the first 21 days posttransplant in 9 LT recipients with HCV genotype 1 infection. As a control group, 7 nontreated recipients were included. Silibinin led to a significant decrease of viral load $(-4.1 \pm 1.3 \mathrm{log})$, and $44 \%$ of the treated patients achieved undetectable HCV RNA while on treatment. As expected, all patients relapsed after silibinin withdrawal. No significant adverse events were observed during silibinin administration. Nevertheless, there have been previous reports of successful treatment of established graft hepatitis with intravenous silibinin plus standard therapy in patients after LT. $^{101}$

Fortunately, three multicentric clinical trials using oral DAAs are recruiting patients to assess the safety and efficacy of these regimens in hepatitis $C$ recurrence: (1) ABT450/ $\mathrm{r}+\mathrm{ABT} 267+\mathrm{ABT} 333+\mathrm{RBV} 24$ weeks in patients with $\leq$ F2 fibrosis score (NCT01782495) ${ }^{102}$; (2) simeprevir + daclatasvir 24 weeks in patients with $\leq$ F3 $\left(\right.$ NCT01938625) ${ }^{103}$; and (3) sofosbuvir/ledipasvir + ribavirin 12 or 24 weeks in patients with all types of HCV recurrence after LT (NCT01938430)..$^{40}$ Most likely, the approval of these combinations will change the management of these patients in the next 2 years (-Fig. 2B).

\section{Treating before or after Liver Transplantation?}

As discussed above, treatment of patients in the transplant setting can be indicated before or after transplantation, once 
hepatitis $C$ has recurred. Treatment before transplantation seems ideal because apart from preventing infection of the graft, viral clearance may be associated with improvement in liver function, and in some cases, delisting. Nevertheless, PK and particularly safety data are not available for all compounds in individuals with advanced liver disease (patients with Child-Pugh B and C). Thus, it is mandatory to wait for the results of studies addressing these issues. Another potential problem in patients awaiting LT is the uncertainty of treatment duration, which cannot be predicted due to the inherent complexity of the waiting list. Finally, regimens used in this setting should have a high barrier to resistance to minimize the risk of virological breakthrough or relapse.

In the near future, it is very likely that all patients awaiting LT will be candidates to receive antiviral therapy while awaiting an organ, as occurs with hepatitis B. Data from studies conducted in immunocompetent patients strongly suggest that some drug combinations will be able to prevent infection of the graft in most cases (-Fig. 1B).

Regarding treatment after LT, there are a few issues to consider. First, PK and safety data are also needed in this patient population, particularly for individuals with advanced liver disease. Second, drug-drug interaction studies are relevant because CsA and tacrolimus undergo metabolism through the CYP3A4 system and have a narrow therapeutic range. Interactions may occur not only with immunosuppressants, but also with other commonly used drugs (e.g., statins, some antihypertensive drugs). The use of regimens with a high barrier to resistance is also relevant, particularly if used early after LT because at this stage HCV-RNA levels can be very high.

Finally, there are several patients who have already developed graft damage following transplantation and in whom the only choice in the coming years will be IFN-free regimens. These patients include nonresponders to IFN-based regimens (including those with a first generation PI), individuals intolerant or unable to receive IFN (comorbidities are frequent in this population), and patients with decompensated cirrhosis (-Fig. 2B). In the latter group the use of IFN-free regimens could allow retransplantation avoiding HCV graft infection.

\section{Conclusions}

Both HCV-infected patients awaiting LT and patients with hepatitis $C$ recurrence will benefit dramatically from these new antiviral regimens. Very soon, hepatitis $C$ will not be "the problem" of transplant programs anymore and will show excellent results after LT as occurred with hepatitis B some years ago. One can only hope that these regimens become available for all patients and that their use is not restricted by cost.

\section{References}

1 Lange CM, Zeuzem S. Perspectives and challenges of interferonfree therapy for chronic hepatitis C. J Hepatol 2013;58(3):583-592

2 Garcia-Retortillo M, Forns X, Feliu A, et al. Hepatitis C virus kinetics during and immediately after liver transplantation. Hepatology 2002;35(3):680-687
3 Crespo G, Mariño Z, Navasa M, Forns X. Viral hepatitis in liver transplantation. Gastroenterology 2012;142(6):1373-1383, e1

4 Londoño MC, Crespo G, Forns X. Pretransplant and posttransplant treatment of hepatitis $C$ virus infection with protease inhibitors. Curr Opin Organ Transplant 2013;18(3):271-278

5 Forns X, García-Retortillo M, Serrano T, et al. Antiviral therapy of patients with decompensated cirrhosis to prevent recurrence of hepatitis C after liver transplantation. J Hepatol 2003;39(3): 389-396

6 Peng CY, Chien RN, Liaw YF. Hepatitis B virus-related decompensated liver cirrhosis: benefits of antiviral therapy. J Hepatol 2012;57(2):442-450

7 Kim WR, Terrault NA, Pedersen RA, et al. Trends in waiting list registration for liver transplantation for viral hepatitis in the United States. Gastroenterology 2009;137(5):1680-1686

8 Iacobellis A, Siciliano M, Perri F, et al. Peginterferon alfa-2b and ribavirin in patients with hepatitis $C$ virus and decompensated cirrhosis: a controlled study. J Hepatol 2007;46(2):206-212

9 Carrión JA, Martínez-Bauer E, Crespo G, et al. Antiviral therapy increases the risk of bacterial infections in HCV-infected cirrhotic patients awaiting liver transplantation: A retrospective study. J Hepatol 2009;50(4):719-728

10 Everson GT, Terrault NA, Lok AS, et al; Adult-to-Adult Living Donor Liver Transplantation Cohort Study. A randomized controlled trial of pretransplant antiviral therapy to prevent recurrence of hepatitis $C$ after liver transplantation. Hepatology 2013; 57(5):1752-1762

11 Everson GT, Trotter J, Forman L, et al. Treatment of advanced hepatitis $C$ with a low accelerating dosage regimen of antiviral therapy. Hepatology 2005;42(2):255-262

12 Coto-Llerena M, Pérez-Del-Pulgar S, Crespo G, et al. Donor and recipient IL28B polymorphisms in HCV-infected patients undergoing antiviral therapy before and after liver transplantation. Am J Transplant 2011;11(5):1051-1057

13 Poordad F, McCone J Jr, Bacon BR, et al; SPRINT-2 Investigators. Boceprevir for untreated chronic HCV genotype 1 infection. N Engl J Med 2011;364(13):1195-1206

14 Jacobson IM, McHutchison JG, Dusheiko G, et al; ADVANCE Study Team. Telaprevir for previously untreated chronic hepatitis $C$ virus infection. N Engl J Med 2011;364(25):2405-2416

15 Sherman KE, Flamm SL, Afdhal NH, et al; ILLUMINATE Study Team. Response-guided telaprevir combination treatment for hepatitis $C$ virus infection. N Engl J Med 2011;365(11):1014-1024

16 Bacon BR, Gordon SC, Lawitz E, et al; HCV RESPOND-2 Investigators. Boceprevir for previously treated chronic HCV genotype 1 infection. N Engl J Med 2011;364(13):1207-1217

17 Zeuzem S, Andreone P, Pol S, et al; REALIZE Study Team. Telaprevir for retreatment of HCV infection. N Engl J Med 2011; 364(25):2417-2428

18 Fontaine H, Hezode C, Dorival C, et al. SVR12 rates and safety of triple therapy including telaprevir or boceprevir in 221 cirrhotic non-responders treated in the French early access program (ANRS CO20-CUPIC). J Hepatol 2013;58:S27

19 Hézode C, Fontaine H, Dorival C, et al; CUPIC Study Group. Triple therapy in treatment-experienced patients with HCV-cirrhosis in a multicentre cohort of the French Early Access Programme (ANRS CO20-CUPIC) - NCT01514890. J Hepatol 2013;59(3):434-441

20 Rutter K, Ferlitsch A, Maieron A, et al. Safety of triple therapy with telaprevir or boceprevir in hepatitis $C$ patients with advanced disease- predictive factors for sepsis. J Hepatol 2013;58:S30

21 Verna EC, Terry N, Lukose T, et al. High early response rates with protease inhibitor triple therapy in a multicenter cohort of HCVinfected patients awaiting liver transplantation. Hepatology 2012;56(Suppl 1):218A

22 Jacobson IM, Yoshida EM, Sulkowski MS, et al. Treatment with sofosbuvir + ribavirin for 12 weeks achieves SVR 12 of $78 \%$ in G2/3 interferon-ineligible, -intolerant, or - unwilling: results of the phase 3 positron trial. J Hepatol 2013;58:S28 
23 Lawitz E, Mangia A, Wyles D, et al. Sofosbuvir for previously untreated chronic hepatitis C infection. N Engl J Med 2013; 368(20):1878-1887

24 Jacobson IM, Gordon SC, Kowdley KV, et al; POSITRON Study; FUSION Study. Sofosbuvir for hepatitis C genotype 2 or 3 in patients without treatment options. N Engl J Med 2013; 368(20):1867-1877

25 Zeuzem S, Dusheiko G, Salupere R, et al. Sofosbuvir and Ribavirin for 12 or 24 Weeks for Patients with HCV Genotype 2 or 3: the VALENCE trial. Hepatology 2013;58(Suppl 1):733A

26 Osinusi A, Meissner EG, Lee YJ, et al. Sofosbuvir and ribavirin for hepatitis $C$ genotype 1 in patients with unfavorable treatment characteristics: a randomized clinical trial. JAMA 2013;310(8): 804-811

27 Lalazeri J, Nelson D, Hyland R, et al. Once-daily sofosbuvir plus ribavirin given for 12 or 24 weeks in treatment-naïve patients with HCV: the QUANTUM study. J Hepatol 2013;58(Suppl 1):S346

28 Gane EJ, Stedman CA, Hyland RH, et al. Efficacy of nucleotide polymerase inhibitor sofosbuvir plus the NS5A inhibitor ledipasvir or the NS5B non-nucleoside inhibitor GS-9669 against HCV genotype 1 infection. Gastroenterology 2013; [Epub ahead of print]

29 Kohli A, Sims Z, Marti M, et al. Combination oral, ribavirin free, antiviral therapy to optimize treatment outcomes for hepatitis $C$ treatment naïve patients: interim results from the NIAID SYNERGY trial. Late breaking abstract (LB 8). Paper presented at: 64th Annual Meeting of the American Association for the Study of Liver Diseases; November 1-5, 2013; Washington, DC

30 Jacobson I, Ghalib R, Rodriguez-Torres M, et al. SVR results of a once-daily regimen of Simeprevir (TMC435) plus Sofosbuvir (GS7977) with or without ribavirin in cirrhotic and non-cirrhotic HCV genotype 1 treatment naïve and prior null responder patients: the COSMOS study. Late breaking abstract (LB 3). Paper presented at: 64th Annual Meeting of the American Association for the Study of Liver Diseases; November 1-5, 2013; Washington, DC

31 Lawitz E, Poordad FF, Pang PS, et al. Sofosbuvir and ledipasvir fixed-dose combination with and without ribavirin in treatmentnaive and previously treated patients with genotype 1 hepatitis $C$ virus infection (LONESTAR): an open-label, randomised, phase 2 trial. Lancet 2013; [Epub ahead of print]

32 Everson G, Sims K, Thuluvath P, et al. Phase 2b study of the interferon-free and ribavirin-free combination of daclatasvir, asunaprevir and BMS-791325 for 12 weeks in treatment-naive patients with chronic HCV genotype 1 infection. Late breaking abstract (LB 1). Paper presented at: 64th Annual Meeting of the American Association for the Study of Liver Diseases; November 1-5, 2013; Washington, DC

33 Ruane P, Ain D, Riad J, et al. Sofosbuvir plus ribavirin in the treatment of chronic HCV genotype 4 infection in patients of Egyptian ancestry. Hepatology 2013;58(Suppl 1):736A

34 Chayama K, Suzuki Y, Ikeda K, et al. All-oral combination of daclatasvir plus asunaprevir in interferon ineligible naive/intolerant and nonresponder Japanese patients chronically infected with HCV genotype 1b: results from a phase 3 trial. Hepatology 2013;58(Suppl 1):313a

35 Zeuzem S, Soriano V, Asselah T, et al. Faldaprevir and deleobuvir for HCV genotype 1 infection. N Engl J Med 2013;369(7):630-639

36 Dufour J-F, Buti M, Soriano V, et al. Interferon-free treatment with faldaprevir, deleobuvir (bi 207127) and ribavirin in SOUND-C3: 95\% SVR12 in HCV-GT1b. Hepatology 2013;58(Suppl 1):744A

37 ClinicalTrials.gov. A study to evaluate the safety and effect of aBT450, ritonavir and ABT-267 (ABT-450/r/ABT-267) and ABT-333 coadministered with ribavirin (RBV) in hepatitis $C$ virus $(\mathrm{HCV})$ genotype 1-infected adults with compensated cirrhosis. Available at: http://www.clinicaltrials.gov/ct2/results?term $=$ NCT01704755\& Search=Search. Accessed February 18, 2014
38 Canini L, DebRoy S, Mariño Z, et al. Hepatitis C virus kinetic comparison between non-cirrhotic patients and patients awaiting liver transplantation treated with intravenous silibinin monotherapy. Hepatology 2013;58(Suppl 1):758A

39 Polyak SJ, Oberlies NH, Pécheur EI, Dahari H, Ferenci P, Pawlotsky JM. Silymarin for HCV infection. Antivir Ther 2013;18(2): $141-147$

40 ClinicalTrials.gov. Sofosbuvir/ledipasvir fixed-dose combination + ribavirin in subjects with chronic HCV with advanced liver disease or post-liver transplant. Available at: http://www. clinicaltrials.gov/ct2/results?term=NCT02010255\&Search $=$ Search. Accessed February 18, 2014

41 Guidance for industry pharmacokinetics in patients with impaired hepatic function: study design, data analysis, and impact on dosing and labeling. Available at: http://www.fda.gov/ downloads/Drugs/GuidanceComplianceRegulatoryInformation/ Guidances/ucm072123.pdf. Accessed February 18, 2014

42 Sekar V, Simion A, Peeters M, et al. Pharmacokinetics of TMC435 in subjects with moderate hepatic impairment. J Hepatol 2011;54 (Suppl 1):S193

43 Simion A, Mortier S, Peeters M, et al. Pharmacokinetics of simeprevir (TMC435) in volunteers with severe renal impairment. Paper presented at: 8th Hepatitis PK Workshop; June 26-27, 2013; Cambridge, MA

44 Soriano V, Gane EJ, Angus P, et al. Efficacy and safety of the interferon (IFN)-free combination of BI $201335+$ BI $207127 \pm$ ribavirin (RBV) in treatment-naïve patients with HCV genotype (GT) 1 infection and compensated liver cirrhosis: Results from the SOUND-C2 study. Hepatology 2012;56(Suppl 4):234A

45 Huang F, Moschetti V, Lang B, et al. Pharmacokinetics, safety, and tolerability of faldaprevir in patients with different levels of renal impairment. Hepatology 2013;58(Suppl 1):431A-432A

46 Eley T, He B, Li J, et al. Effect of hepatic impairment on the pharmacokinetics of asunaprevir (BMS-650032, ASV). Hepatology 2012;56(4):1065A

47 Garimella T, He B, Luo W, et al. Asunaprevir pharmacokinetics and safety in subjects with impaired renal function. Hepatology 2013;58(Suppl 1):430A

48 Bifano M, Sevinsky H, Persson A, et al. Single-dose pharmacokinetics of daclatasvir (DCV; BMS-790052) in subjects with hepatic impairment compared with healthy subjects. Hepatology 2011; 54(S1):1004A

49 Lee C. Daclatasvir: potential role in hepatitis C. Drug Des Devel Ther 2013;7:1223-1233

50 ClinicalTrials.gov. Pharmacokinetic and Safety Study of Daclatasvir in Patients With Renal Impairment. Available at: http://www. clinicaltrials.gov/ct2/results?term $=$ NCT01830205\&Search $=$ Search. Accessed February 4, 2014

51 Khatri A, Gaultier I, Menon R, et al. Pharmacokinetics and safety of co-administered ABT-450 plus ritonavir (ABT 450/r), ABT-267 and ABT-333 as a single dose in subjects with normal hepatic function and in subjects with mild, moderate and severe hepatic impairment. Hepatology 2012;56(Suppl 4):555A

52 Tseng A. Drug interactions with investigational hepatitis c protease inhibitors. Available at: http://www.hcvdruginfo.ca/downloads/Hepatitis\%20C-int_new\%20PIs.pdf. Accessed February 18, 2014

53 Mariño Z, van Bommel F, Forns X, et al. New concepts of sofosbuvir-based treatment regimens in patients with hepatitis C. Gut 2014;63(2):207-215

54 Lawitz E, Rodriguez-Torres M, Cornpropst M, et al. The effect of hepatic impairment on the pharmacokinetics and antiviral activity of PSI-7977 in hepatitis C infected subjects treated for seven days. J Hepatol 2012;56(Suppl 2):S445-S446

55 Cornpropst M, Denning J, Clemons D, et al. The effect of renal impairment and end stage renal disease on the single-dose pharmacokinetics of PSI-7977. J Hepatol 2012;56(Suppl 2):S433 
56 German P, Mathias A, Yang J, et al. The pharmacokinetics of ledipasvir, an HCV specific NS5A inhibitor in HCV-uninfected subjects with moderate and severe hepatic impairment. Hepatology 2013;58(Suppl 1):432A

57 Curry MP, Forns X, Chung RT, et al. Pretransplant sofosbuvir and ribavirin to prevent recurrence of $\mathrm{HCV}$ infection after liver transplantation. Hepatology 2013;58(Suppl 1):314A

58 Mariño Z, Crespo G, D'Amato M, et al. Intravenous silibinin monotherapy shows significant antiviral activity in HCV-infected patients in the peri-transplantation period. J Hepatol 2013;58(3): 415-420

59 Rowe IA, Armstrong MJ, Parker R, et al. Scavenger receptor B-I antagonist ITX5061 modulates early HCV kinetics in patients undergoing liver transplantation: results of a phase Ib clinical trial. Hepatology 2013;58(Suppl 1):239A

60 ClinicalTrials.gov. A pilot study to examine the role of nitazoxanide to prevent recurrence of hepatitis $C$ after transplantation. Available at: http://www.clinicaltrials.gov/ct2/show/NCT01074203? term $=$ NCT01074203\&rank=1 Accesssed February 8, 2014

61 Ferenci P, Scherzer TM, Kerschner H, et al. Silibinin is a potent antiviral agent in patients with chronic hepatitis $C$ not responding to pegylated interferon/ribavirin therapy. Gastroenterology 2008;135(5):1561-1567

62 Neumann UP, Biermer M, Eurich D, Neuhaus P, Berg T. Successful prevention of hepatitis $\mathrm{C}$ virus (HCV) liver graft reinfection by silibinin mono-therapy. J Hepatol 2010;52(6):951-952

63 Beinhardt S, Rasoul-Rockenschaub S, Scherzer TM, Ferenci P. Silibinin monotherapy prevents graft infection after orthotopic liver transplantation in a patient with chronic hepatitis C. J Hepatol 2011;54(3):591-592, author reply 592-593

64 Esser-Nobis K, Romero-Brey I, Ganten TM, et al. Analysis of hepatitis $C$ virus resistance to silibinin in vitro and in vivo points to a novel mechanism involving nonstructural protein 4B. Hepatology 2013;57(3):953-963

65 Adam R, McMaster P, O’Grady JG, et al; European Liver Transplant Association. Evolution of liver transplantation in Europe: report of the European Liver Transplant Registry. Liver Transpl 2003; 9(12):1231-1243

66 Belli LS, Burroughs AK, Burra P, et al. Liver transplantation for HCV cirrhosis: improved survival in recent years and increased severity of recurrent disease in female recipients: results of a long term retrospective study. Liver Transpl 2007;13(5):733-740

67 Berenguer M, Ferrell L, Watson J, et al. HCV-related fibrosis progression following liver transplantation: increase in recent years. J Hepatol 2000;32(4):673-684

68 Yilmaz N, Shiffman ML, Stravitz RT, et al. A prospective evaluation of fibrosis progression in patients with recurrent hepatitis $C$ virus following liver transplantation. Liver Transpl 2007;13(7):975-983

69 Walter T, Dumortier J, Guillaud O, Hervieu V, Scoazec JY, Boillot O. Factors influencing the progression of fibrosis in patients with recurrent hepatitis $C$ after liver transplantation under antiviral therapy: a retrospective analysis of 939 liver biopsies in a single center. Liver Transpl 2007;13(2):294-301

70 Neumann UP, Berg T, Bahra M, et al. Fibrosis progression after liver transplantation in patients with recurrent hepatitis C. J Hepatol 2004;41(5):830-836

71 Forman LM, Lewis JD, Berlin JA, Feldman HI, Lucey MR. The association between hepatitis $C$ infection and survival after orthotopic liver transplantation. Gastroenterology 2002; 122(4):889-896

72 Gane EJ. The natural history of recurrent hepatitis $C$ and what influences this. Liver Transpl 2008;14(Suppl 2):S36-S44

73 Garcia-Retortillo M, Forns X. Prevention and treatment of hepatitis C virus recurrence after liver transplantation. J Hepatol 2004; 41(1):2-10

74 Gane EJ, Naoumov NV, Qian KP, et al. A longitudinal analysis of hepatitis C virus replication following liver transplantation. Gastroenterology 1996;110(1):167-177
75 Sánchez-Fueyo A, Restrepo JC, Quintó L, et al. Impact of the recurrence of hepatitis $C$ virus infection after liver transplantation on the long-term viability of the graft. Transplantation 2002; 73(1):56-63

76 Neumann UP, Berg T, Bahra M, et al. Long-term outcome of liver transplants for chronic hepatitis C: a 10-year follow-up. Transplantation 2004;77(2):226-231

77 Blasco A, Forns X, Carrión JA, et al. Hepatic venous pressure gradient identifies patients at risk of severe hepatitis $C$ recurrence after liver transplantation. Hepatology 2006;43(3):492-499

78 Berenguer M, Palau A, Aguilera V, Rayón JM, Juan FS, Prieto M. Clinical benefits of antiviral therapy in patients with recurrent hepatitis C following liver transplantation. Am J Transplant 2008; 8(3):679-687

79 Wang CS, Ko HH, Yoshida EM, Marra CA, Richardson K. Interferonbased combination anti-viral therapy for hepatitis $C$ virus after liver transplantation: a review and quantitative analysis. Am J Transplant 2006;6(7):1586-1599

80 Xirouchakis E, Triantos C, Manousou P, et al. Pegylated-interferon and ribavirin in liver transplant candidates and recipients with HCV cirrhosis: systematic review and meta-analysis of prospective controlled studies. J Viral Hepat 2008;15(10):699-709

81 Coilly A, Roche B, Samuel D. Current management and perspectives for HCV recurrence after liver transplantation. Liver Int 2013;33(Suppl 1):56-62

82 Chalasani N, Manzarbeitia C, Ferenci P, et al; Pegasys Transplant Study Group. Peginterferon alfa-2a for hepatitis C after liver transplantation: two randomized, controlled trials. Hepatology 2005;41(2):289-298

83 Samuel D, Bizollon T, Feray C, et al. Interferon-alpha 2b plus ribavirin in patients with chronic hepatitis $\mathrm{C}$ after liver transplantation: a randomized study. Gastroenterology 2003;124(3): 642-650

84 Carrión JA, Navasa M, García-Retortillo M, et al. Efficacy of antiviral therapy on hepatitis $C$ recurrence after liver transplantation: a randomized controlled study. Gastroenterology 2007; 132(5):1746-1756

85 Faisal N, Renner EL, Bilodeau M, et al. Protease inhibitor-based triple therapy is highly effective in liver transplant recipients with genotype 1 hepatitis $C$ recurrence: A Canadian multicentre experience. Hepatology 2013;58(Suppl 1):238A

86 Coilly A, Dumortier J, Botta-Fridlund D. Sustained virological response after protease inhibitor based therapy for hepatitis $C$ recurrence after liver transplantation: a multicentric European experience. Hepatology 2013;58(Suppl 1):316A

87 Coilly A, Roche B, Dumortier J, et al. Safety and efficacy of protease inhibitors to treat hepatitis $C$ after liver transplantation: A multicenter experience. J Hepatol 2014;60(1):78-86

88 Brown KA, Fontana RJ, Russo MW, et al. Twice daily telaprevir in combination with Peginterferon alfa 2a/Ribavirin in genotype 1 HCV liver transplant recipients: interim week 16 safety and efficacy results of hte prospective multicentre REFRESH study. Hepatology 2013;58(Suppl 1):209A

89 Verna EC, Burton JR Jr, O' Leary JG, et al. A multicenter study of protease inhibitor-triple therapy in $\mathrm{HCV}$-infected liver transplant recipients: report from the CRUSH-C group. J Hepatol 2013;51 (Suppl 1):S10

90 Stravitz R, Levitsky J, Dodge J, et al. Higher sustained virologic response (SVR-12) achievable in liver transplant (LT) recipients with hepatitis C (HCV) treated with protease inhibitor (PI) triple therapy (TT). Hepatology 2013;58(Suppl 1):429A

91 Hulskotte E, Gupta S, Xuan F, et al. Pharmacokinetic interaction between the hepatitis $C$ virus protease inhibitor boceprevir and cyclosporine and tacrolimus in healthy volunteers. Hepatology 2012;56(5):1622-1630

92 Garg V, van Heeswijk R, Lee JE, Alves K, Nadkarni P, Luo X. Effect of telaprevir on the pharmacokinetics of cyclosporine and tacrolimus. Hepatology 2011;54(1):20-27 
93 Coilly A, Furlan V, Roche B, et al. Practical management of boceprevir and immunosuppressive therapy in liver transplant recipients with hepatitis $C$ virus recurrence. Antimicrob Agents Chemother 2012;56(11):5728-5734

94 Mathias A, Cornpropst M, Clemons D, et al. No clinically significant pharmacokinetic drug-drug interactions between sofosbuvir (GS7977) and the immunosuppressants, cyclosporine $A$ or tacrolimus in healthy volunteers. Hepatology 2012;56(Suppl 1): 1063A-1064A

95 Ouwerkerk-Mahadevan S, Simion A, Mortier S, et al. No clinically significant interaction between the investigational HCV protease inhibitor TMC435 and the immunosuppressives cyclosporine and tacrolimus. Hepatology 2012;56(Suppl 1):231A

96 Fontana RJ, Hughes EA, Appelman H, Hindes R, Dimitrova D, Bifano M. Case report of successful peginterferon, ribavirin, and daclatasvir therapy for recurrent cholestatic hepatitis $\mathrm{C}$ after liver retransplantation. Liver Transpl 2012;18(9):1053-1059

97 Charlton M, Gane EJ, Manns M, Forns X. Sofosbuvir and ribavirin for the treatment of established recurrent hepatitis $C$ infection after liver transplantation: preliminary results of a prospective, multicenter study. Late-breaking abstract (LB 2). Paper presented at: the 64th Annual Meeting of the American Association for the Study of Liver Diseases; November 1-5, 2013; Washington, DC

98 Forns X, Fontana RJ, Moonka D, et al. Initial evaluation of the sofosbuvir compassionate use program for patients with severe recurrent HCV following liver transplantation. Hepatology 2013; 58(Suppl 1):732A
99 Fontana RJ, Hughes EA, Bifano M, et al. Sofosbuvir and daclatasvir combination therapy in a liver transplant recipient with severe recurrent cholestatic hepatitis C. Am J Transplant 2013;13(6): 1601-1605

100 Bárcena R, Moreno A, Rodríguez-Gandía MA, et al; Hospital Ramón y Cajal Liver Transplant Group. Safety and anti-HCV effect of prolonged intravenous silibinin in HCV genotype 1 subjects in the immediate liver transplant period. J Hepatol 2013;58(3): 421-426

101 Eurich D, Bahra M, Berg T, et al. Treatment of hepatitis C-virusreinfection after liver transplant with silibinin in nonresponders to pegylated interferon-based therapy. Exp Clin Transplant 2011; $9(1): 1-6$

102 ClinicalTrials.gov. A study to evaluate chronic hepatitis $C$ infection in adult liver transplant recipients. Available at: http://www. clinicaltrials.gov/ct2/results?term $=$ NCT01782495\&Search=Search. Accessed February 18, 2014

103 ClinicalTrials.gov. A study of pharmacokinetics, efficacy, safety, tolerability, of the combination of simeprevir (TMC435), daclatasvir (BMS-790052), and ribavirin (RBV) in patients with recurrent chronic hepatitis C Genotype 1b infection after orthotopic liver transplantation. Available at: http://www.clinicaltrials.gov/ ct2/results?term $=$ NCT01938625\&Search $=$ Search. Accessed February 18, 2014

104 Sulkowski MS, Gardiner DF, Rodriguz-Torres M, et al. Daclatasvir plus Sofobovir for previously treated or untreated chronic HCV infection. N Engl J Med 2014;370:211-212 